\title{
Identification of Cystoisospora ohioensis in a Diarrheal Dog in Korea
}

\author{
Sangmin Lee', Junki Kim¹, Doo-Sung Cheon², Eun-A Moon³, Dong Joo Seo", Soontag Jung ${ }^{5}$, \\ Hansaem Shin ${ }^{5}$, Changsun Choi,** \\ 'Banghak Animal Hospital, Seoul 01350; '²Pobanilab Veterinary Clinic, Guri 11906; ${ }^{3}$ Department of Electronic Engineering, Chosun University, \\ Gwangju 61452; ' ${ }^{4}$ Department of Food and Nutrition, Gwangju University, Gwangju 61743; "5Department of Food and Nutrition, Chung-Ang \\ University, Anseong 17546, Korea
}

\begin{abstract}
A 3-month-old female Maltese puppy was hospitalized with persistent diarrhea in a local veterinary clinic. Blood chemistry and hematology profile were analyzed and fecal smear was examined. Diarrheal stools were examined in a diagnostic laboratory, using multiplex real-time polymerase chain reaction (PCR) against 23 diarrheal pathogens. Sequence analysis was performed using nested PCR amplicon of $18 \mathrm{~S}$ ribosomal RNA. Coccidian oocysts were identified in the fecal smear. Although multiplex real-time PCR was positive for Cyclospora cayetanensis, the final diagnosis was Cystoisospora ohioensis infection, confirmed by phylogenetic analysis of 18S rRNA. To our knowledge, this the first case report of $C$. ohioensis in Korea, using microscopic examination and phylogenetic analysis.
\end{abstract}

Key words: Cystoisospora ohioensis, dog, infection, 18S ribosomal RNA, phylogenetic analysis

\section{INTRODUCTION}

In humans, cyclosporiasis and cystoisosporiasis are frequently associated with immunocompromised patients worldwide [1]. Recently, canine cyclosporiasis and cystoisosporiasis have been reported. Cyclospora cayetanensis is considered an important pathogen in humans and vertebrates since human cyclosporiasis was first identified in diarrheal patients from Papua New Guinea [2]. The genus Cyclospora comprises obligate intracellular coccidian protozoa that reside in the intestinal epithelium and bile duct of hosts [2]. C. cayetanensis is transmitted through water-borne, soil-borne, and food-borne routes in developing and developed countries [2]. To date, Cylospora-like organisms or C. cayetanenensis have been detected in dairy cattle, Macaca mulatta rhesus monkey, wild chicken, and dogs [2].

Cystoisospora canis, C. ohioensis, and C. burrowsi cause diarrhea in puppies $<6$ months of age and immunocompromised dogs [3]. Although C. canis is the prevalent Cystoisospora species in dogs, C. ohioensis is frequently detected in Chinese dogs [4].

\footnotetext{
- Received 9 March 2018, revised 26 July 2018, accepted 26 July 2018.

*Corresponding author (cchoi@cau.ac.kr)

(C) 2018, Korean Society for Parasitology and Tropical Medicine

This is an Open Access article distributed under the terms of the Creative Commons Attribution Non-Commercial License (http://creativecommons.org/licenses/by-nc/4.0) which permits unrestricted non-commercial use, distribution, and reproduction in any medium, provided the original work is properly cited.
}

Recently, Japanese raccoon dogs were identified as the reservoir host of $C$. ohioensis [5]. However, no clinical cases of canine cystoisosporiasis have been reported to date in Korea although experimental infection and sporulation of $C$. ohioensis isolates have been performed in Korean puppies [6].

It is difficult for veterinary clinicians to diagnose cyclosporiasis and cystoisosporiasis based on clinical signs alone. The morphological similarity of Cyclospora and Cystoisospora oocyst hinders microscopic diagnosis using stools. Thus, both microscopic examination and molecular techniques for differential diagnosis are used $[4,5]$. The present study aimed to describe a clinical case in which the protozoan pathogen $C$. ohioensis was identified in a Korean dog, using microscopy of diarrheal stools and confirmed using phylogenetic analysis of $18 \mathrm{~S}$ ribosomal RNA (rRNA).

\section{CASE RECORD}

A 3-month-old female Maltese puppy was hospitalized with mild to moderate symptoms of repetitive diarrhea, dehydration, and reduced appetite in a local veterinary clinic. Microscopic examination of fecal smear was performed. Blood chemistry and hematology profile were analyzed using the Fuji DRI-CHEM NX500 automated clinical chemistry analyzer (Fuji, Tokyo, Japan) and veterinary hematology analyzer PE- 
Table 1. Hematology profile and blood chemistry of a diarrheal puppy infected with Cystoisospora ohioensis

\begin{tabular}{|c|c|}
\hline Test & Result \\
\hline White blood cell & $14 \times 10^{3} / \mu l(5-20)$ \\
\hline Red blood cell & $5.76 \times 10^{6} / \mu \mathrm{l}(5.5-8.5)$ \\
\hline Platelet & $615 \times 10^{3} / \mu \mathrm{l}(100-500)$ \\
\hline Hemoglobin & $12.7 \mathrm{~g} / \mathrm{dl}(11-19)$ \\
\hline Hematocrit & $39.8 \%(39-56)$ \\
\hline MCV & $69.1 \mathrm{fl}(60-74)$ \\
\hline $\mathrm{MCH}$ & $22 \mathrm{pg}(19.5-24.5)$ \\
\hline $\mathrm{MCHC}$ & $31.9 \mathrm{~g} / \mathrm{dl}(28-40)$ \\
\hline Lymphocytes & $47.6 \%(10-40)$ \\
\hline Monocytes & $4.9 \%(3-14)$ \\
\hline Neutrophils & $47.5 \%(50-80)$ \\
\hline Eosinophils & ND\% (2-10) \\
\hline Basophils & ND\% (0-2.5) \\
\hline Lymphocytes & $6.7 \times 10^{3} / \mu \mathrm{l}(0.5-6.0)$ \\
\hline Monocytes & $0.7 \times 10^{3} / \mu \mathrm{l}(0.2-2.0)$ \\
\hline Neutrophils & $6.6 \times 10^{3} / \mu l(4-15)$ \\
\hline Eosinophils & $\mathrm{ND} \times 10^{3} / \mu \mathrm{l}(0.1-1.3)$ \\
\hline Basophils & $\mathrm{ND} \times 10^{3} / \mu \mathrm{l}(0-0.5)$ \\
\hline Total protein & $4.5 \mathrm{~g} / \mathrm{dl}(5-7.2)$ \\
\hline ALT/SGPT & $28 \mathrm{U} / \mathrm{L}(17-78)$ \\
\hline AST/SGOT & 40 U/L (9-69) \\
\hline ALP & 484 U/L (69-333) \\
\hline $\mathrm{Na}$ & 140 mEq/L (141-152) \\
\hline K & 4.8 mEq/L (3.8-5.0) \\
\hline $\mathrm{Cl}$ & 106 mEq/L (102-117) \\
\hline
\end{tabular}

MCV, Mean corpuscular volume; MCH, Mean corpuscular hemoglobin; $\mathrm{MCHC}$, Mean corpuscular hemoglobin concentration; ND, Not detected.

6800 VET (Prokan, Shenzhen, China), respectively.

Blood chemistry analysis showed that total protein and sodium concentrations were slightly lower than the normal range (Table 1). Because vomiting and diarrhea lead to decreased total protein and sodium concentrations, these results were consistent with the observed symptoms. In contrast, the concentration of alkaline phosphatase (ALP) (484 U/L) was higher than the normal concentration. Although high ALP concentration is associated with hepatic damage, it is frequently observed in normal puppies. Total white blood cells and red blood cells were in the normal range. Remarkably, the number of lymphocytes and neutrophils were $6.7 \times 10^{3} / \mu \mathrm{l}$ and $6.6 \times 10^{3} /$ $\mu \mathrm{l}$, respectively. The percentage of lymphocytes and neutrophils were $47.6 \%$ and $47.5 \%$, respectively.

Fecal smears fixed with $3 \%$ acid alcohol were stained with boiling safranin and counter-stained with hematoxylin. The microscopic image was acquired and analyzed by LAS V4.1 software (Leica Microsystems, Frankfurt, German). Phase-contrast microscopy showed that the fecal smears were negative

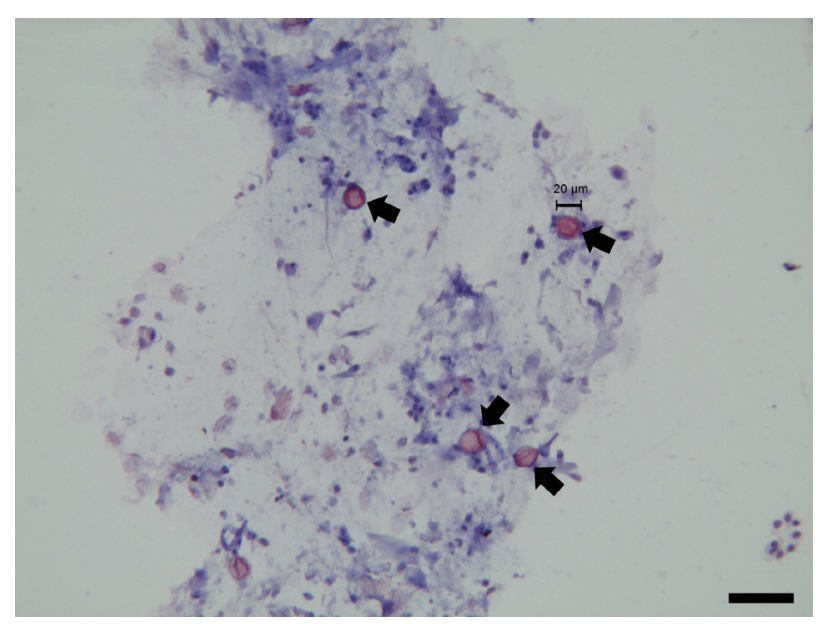

Fig. 1. Cystoisospora ohioensis oocysts (arrows) with modified safranin staining. Scale bar is $50 \mu \mathrm{m}$.

for spirochetes. Coccidian oocysts were clearly observed in the fecal smears (Fig. 1). All oocysts were 20 to $22 \mu \mathrm{m}$ in diameter, with an oval structure, and appeared refractile. The oocysts were stained red, with more intense staining at the edges than at the center. However, because the internal structure of the oocysts was not clearly determined, the genus of the pathogen could not be confirmed based on microscopic morphology.

Diarrheal stools were collected and transported to POBANILAB, an animal hospital specialized in infection and allergy diagnostics. Immunochromatographic assay, multiplex real-time polymerase chain reaction (PCR), and reverse transcription PCR (RT-PCR) were performed at POBANILAB using POBGEN canine enteric pathogen detection kits (POSTBIO, Hanam, Korea) for 23 enteric pathogens, including canine distemper, parvovirus, coronavirus, norovirus, circovirus, astrovirus, sapovirus, group A rotavirus, Clostridium perfringens, Campylobacter jejuni, Campylobacter coli, Salmonella species, enterotoxigenic Escherichia coli, enteropathogenic E. coli, enterohemorrhagic E. coli, enteroinvasive E. coli, Lawsonia intracellularis, Cryptosporidium parvum, Giardia lamblia, Entamoeba histolytica, C. cayetanensis, Toxoplasma gondii, and Toxocara canis. Although all laboratory tests were negative for 8 canine viruses, 9 bacteria, and 5 other parasites, multiplex real-time PCR showed a positive reaction only for $C$. cayetanensis. Considering that the threshold cycle value of C. cayetanensis was as high as $28.8, C$. cayetanensis was suspected to be responsible for the diarrhea.

In order to confirm coccidian organisms in fecal samples, sequence analysis was performed as described previously [7]. For primary PCR, ExCycF (5'-AAT GTA AAA CCC TTC CAG AGT 


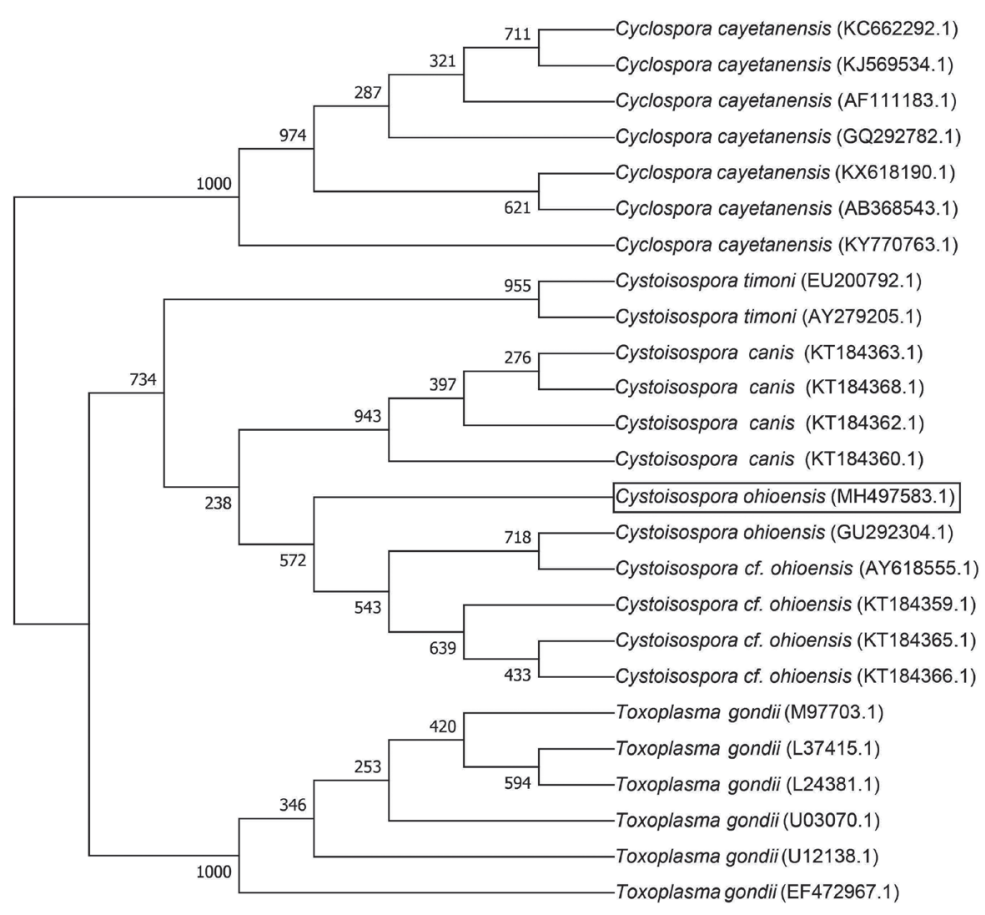

Fig. 2. Phylogenetic tree of the $18 \mathrm{~S}$ ribosomal RNA gene sequences. Bootstrap values for 1,000 replicates for neighbor-joining analysis are indicated.

AAC-3') and ExCycR (5'-GCA ATA ATC TAT CCC CAT CAC G-3') were used to amplify $18 \mathrm{~S}$ ribosomal RNA locus. Nested PCR was performed with NesCycF (5'-AAT TCC AGC TCC AAT AGT GTA T-3') and NesCycR (5'-CAG GAG AAG CCA AGG TAG GCR TTT$3^{\prime}$ ). A 498-bp nested PCR product was confirmed on a 1\% agarose gel and purified. The purified PCR product was cloned in competent E. coli using an All in One ${ }^{\mathrm{TM}}$ PCR Cloning Kit (Biofact, Deajeon, Korea). Sequencing was performed with ABI 3730XL DNA Analyzer (Applied Biosystems, California, USA) using the Sanger dideoxy method. C. cayetanensis, C. ohioensis, C. canis, C. timonii, and T. gondii were used as outgroup species. Sequence alignment of 18S rRNA was performed using ClustalX2.1 (http:// softadvice.informer.com/Clustalx_2.1.html). The phylogenetic tree was analyzed using the neighbor joining method and generated using MEGA7 (http://www.megasoftware.net/).

Sequence data of $18 \mathrm{~S}$ rRNA obtained in this study were deposited in Genbank at the National Center for Biotechnology Information (Accession no. MH497583.1). Phylogenetic analysis of $18 \mathrm{~S}$ rRNA sequence showed a $98.79 \%$ homology with the C. ohioensis sequence (GenBank Accession No. AY618555.1) (Fig. 2). However, sequence analysis did not match with any of C. cayetanensis sequences. On the basis of all data, the final diagnosis of this case was confirmed as $C$. ohioensis infection.

\section{DISCUSSION}

This study focused on the detection of C. cayetanensis by multiplex PCR; however, the final diagnosis of this case was $C$. ohioensis infection, confirmed by sequence analysis. Recently, C. cayetanensis was identified in the diarrheal stools of dogs in Nepal and Brazil [1]. It has also been reported that some human cyclosporiasis cases in Guatemala, Peru, Nepal, Jordan, and Egypt may be associated with contact with C. cayetanensis-infected animals [2]. However, C. cayetanensis experimental infection in mouse, rat, sand rat, chicken, duck, rabbit, hamster, ferret, pig, dog, owl monkey, rhesus monkey, and cynomolgus monkey have failed [9]. Although zoonotic potential of C. cayetanensis seems to be low, public health guidelines emphasize on preventing its transmission from companion animals to humans. Canine cyclosporiasis has not been documented in Korea to date; however, it is necessary to monitor it in future research.

To our knowledge, this is the first phylogenetic analysis of $C$. ohioensis isolates confirmed in a veterinary clinic in Korea. Previous studies have reported high prevalence of canine cystoisosporiasis: $8.7 \%$ in Austria, $5.7 \%$ in north-eastern Italy, and $5.1 \%$ in the United Kingdom [3]. C. canis was the prevalent species in the United Kingdom, whereas C. ohioensis was preva- 
lent in Australia, Japan, and China [3-5]. Although other coccidian parasites are not associated with peripheral eosinophilia, it is known that cystoisosporiasis causes eosinophilic enteritis [1]. However, veterinary clinicians could not observe peripheral eosinophilia in the hematology profile (Table 1). The veterinary hematology analyzer commonly used in Korea has only 3 channels for lymphocytes, monocytes, and neutrophils; this limitation might hinder the diagnosis of $C$. ohioensis in dogs.

Notably, nested PCR primers described in a previous study [7] detected not only C. cayetanensis but also C. ohioensis because the $18 \mathrm{~S}$ rRNA gene is frequently used to detect protozoa $[4,5,7,8]$. In some previous studies, $18 \mathrm{~S}$ rRNA for C. cayetanensis and 5.8S rRNA and ITS2 region for Cystoisospora belli were used for the development of multiplex PCR, whereas in other studies, 18S rRNA and ITS1 genes of Cystoisospora spp. were used for phylogenetic analysis $[4,5,8]$. For diagnostic purposes, detection by the $18 \mathrm{~S}$ rRNA gene has limitations in differentiating $C$. cayetanensis from $C$. ohioensis. Therefore, ITS1, which is a high-copy number element of the genome commonly used as a DNA biomarker or DNA barcode, could be a promising target for detecting and differentiating C. ohioensis and C. cayetanensis. After the development of $C$. ohioensis species-specific PCR, its primer specificity should be tested with $C$. cayetanensis.

Based on multiplex real-time PCR and fecal smear analyses, trimethoprim-sulfamethoxazole and metronidazole were initially administered to the puppy for treatment of the condition tentatively diagnosed as canine cyclosporiasis. In general, trimethoprim-sulfamethoxazole is recommended for the treatment of cyclosporiasis and cystoisosporiasis [1]. However, an initial prescription of trimethoprim-sulfamethoxazole did not improve the clinical signs of this case. A combination of clavamox (amoxicillin trihydrate/clavulanate potassium) and metronidazole was effective in the treatment of diarrhea in this case. Ciprofloxacin is an alternative drug for the treatment of diarrhea in HIV-infected patients or patients allergic to sulfa drugs [1]. Recently, nitazoxanide was used in the treatment of a C. cayetanensis-infected patient who was not responsive to trimethoprim-sulfamethoxazole [10]. Although ciprofloxacin or nitazoxanide was not prescribed in this case, notably, trimethoprim-sulfamethoxazole was not effective. Thus, a combination of clavamox and metronidazole can be considered as an alternative treatment for canine cyclosporiasis.

\section{ACKNOWLEDGMENTS}

This work was supported by Korea Institute of Planning and Evaluation for Technology in Food, Agriculture, Forestry and Fisheries (IPET) through Advanced Production Technology Development Program, funded by Ministry of Agriculture, Food and Rural Affairs (MAFRA) (316021-03-1-SB010).

\section{CONFLICT OF INTEREST}

All authors declared that there is no conflict of interest with respect to the research, authorship, and publication of this article.

\section{REFERENCES}

1. Hechenbleikner EM, McQuade JA. Parasitic colitis. Clin Colon Rectal Surg 2015; 28: 79-86.

2. Chacín-Bonilla L. Epidemiology of Cyclospora cayetanensis: a review focusing in endemic areas. Acta Trop 2010; 115: 181-193.

3. Buehl IE, Prosl H, Mundt HC, Tichy AG, Joachim A. Canine isosporosis - epidemiology of field and experimental infections. J Vet Med B Infect Dis Vet Public Health 2006; 53: 482-487.

4. He P, Li J, Gong P, Huang J, Zhang X. Cystoisospora spp. from dogs in China and phylogenetic analysis of its $18 \mathrm{~S}$ and ITS1 gene. Vet Parasitol 2012; 190: 254-258.

5. Matsubayashi M, Carreno RA, Tani H, Yoshiuchi R, Kanai T, Kimata I, Uni S, Furuya M, Sasai K. Phylogenetic identification of Cystoisospora spp. from dogs, cats, and raccoon dogs in Japan. Vet Parasitol 2011; 176: 270-274.

6. Baek BK, Kim CS, Kim JH, Han KS, Kim YG. Studies on isosporosis in dogs. I: isolation and sporulation of Isospora ohioensis. Korean J Parasitol 1993; 31: 201-206.

7. Sulaiman IM, Ortega Y, Simpson S, Kerdahi K. Genetic characterization of human-pathogenic Cyclospora cayetanensis parasites from three endemic regions at the $18 \mathrm{~S}$ ribosomal RNA locus. Infect Genet Evol 2014; 22: 229-234.

8. Taniuchi M, Verweij JJ, Sethabutr O, Bodhidatta L, Garcia L, Maro A, Kumburu H, Gratz J, Kibiki G, Houpt ER. Multiplex polymerase chain reaction method to detect Cyclospora, Cystoisospora, and Microsporidia in stool samples. Diagn Microbiol Infect Dis 2011; 71: 386-390.

9. Eberhard ML, Ortega YR, Hanes DE, Nace EK, Do RQ, Robl MG, Won KY, Gavidia C, Sass NL, Mansfield K, Gozalo A, Griffiths J, Gilman R, Sterling CR, Arrowood MJ. Attempts to establish experimental Cyclospora cayetanensis infection in laboratory animals. J Parasitol 2000; 86: 577-582.

10. Sánchez-Vega JT1, Cabrera-Fuentes HA, Romero-Olmedo AJ, Ortiz-Frías JL, Sokolina F, Barreto G Cyclospora cayetanensis: this emerging protozoan pathogen in Mexico. Am J Trop Med Hyg 2014; 90: 351-353. 